\title{
Development and validation of methods for environmental monitoring of cyclophosphamide in workplaces
}

\author{
Maria Hedmer, ${ }^{* a}$ Bo A. G. Jönsson ${ }^{a}$ and Olle Nygren ${ }^{b}$ \\ ${ }^{a}$ Department of Occupational and Environmental Medicine, Institute of Laboratory Medicine, \\ University Hospital,SE-22185Lund, Sweden.E-mail: maria.hedmer@ymed.lu.se \\ ${ }^{\boldsymbol{b}}$ National Institute for Working Life, Program for Chemical Exposure Assessment, \\ PO Box 7654, SE-907 13 Umeå, Sweden
}

Received 24th June 2004, Accepted 22nd September 2004

First published as an Advance Article on the web 2nd November 2004

\begin{abstract}
Methods to monitor contamination of workplaces with antineoplastic drugs have been developed and validated. Cyclophosphamide $(\mathrm{CP})$ was used as a model compound as it is one of the most commonly used antineoplastic drugs. A wipe sampling method to detect contamination with CP at surfaces was developed. A personal air sampling method to sample gas and vapour on solid sorbent tubes and particles with filters was also developed. Wipe and filter samples were extracted and sorbent samples were eluted, all with ethyl acetate. The samples were analysed with liquid chromatography tandem mass spectrometry. ${ }^{2} \mathrm{H}_{6}$-labelled cyclophosphamide was used as an internal standard. The between-day precision was $2-5 \%$ for wipe samples, 4-6\% for sorbent samples and 3-8\% for filter samples. The limit of detection was $0.02 \mathrm{ng}$ CP per sample for the wipe and filter methods and $0.03 \mathrm{ng}$ CP per sample for the solid sorbent method. Wipe sampling on surfaces made of different materials resulted in mean recoveries between $78-106 \%$. The desorption recovery was between $97-102 \%$ for the wipe samples, $97 \%$ for the sorbent samples and $101 \%$ for the filter samples. Samples were stable for up to 2 months at $5{ }^{\circ} \mathrm{C}$ and $-20{ }^{\circ} \mathrm{C}$ and for about $2 \mathrm{~d}$ at room temperature. The developed methods were applied to the measurement of contamination with $\mathrm{CP}$ in a hospital pharmacy. Trace amounts of $\mathrm{CP}, 1.3$ and $1.4 \mathrm{ng}$, were detected on surfaces in the pharmacy.
\end{abstract}

\section{Introduction}

Antineoplastic drugs are widely used around the world in medical treatment of different diseases, e.g. cancer. Every day large amounts of antineoplastic drugs are given to patients treated in hospitals, nursing homes and in primary health care. Many antineoplastic drugs are classified as carcinogenic, mutagenic or teratogenic to humans. There are several groups of health care workers including nurses, pharmacy technicians, laboratory staff and cleaners that may be occupationally exposed to antineoplastic drugs. Exposure of workers can occur during preparation or administration of antineoplastic drugs, during nursing and taking care of patients or during cleaning. Absorption of antineoplastic drugs occurs mainly through skin or through inhalation of gases or particles. Occupationally exposed workers have earlier been studied and the levels of antineoplastic drugs or their metabolites in both urine ${ }^{1-5}$ and blood ${ }^{6}$ have been monitored.

Cyclophosphamide (2-[bis(2-chloroethyl)amino]tetrahydro2H-1,3,2-oxazaphosphorine 2-oxide; CP), a very common antineoplastic drug, was introduced in the $1950 \mathrm{~s}^{7} \mathrm{CP}$ is classified as carcinogenic to humans by the International Agency for Research on Cancer (IARC). ${ }^{8,9} \mathrm{CP}$ is a prodrug and its metabolites are genotoxic due to their ability to interact with DNA, causing cross-linking. $\mathrm{CP}$ is used in the treatment of many cancer diseases, as a single drug or in combination with other antineoplastic drugs. CP can therefore be considered as a model compound for identification of exposure during work with antineoplastic drugs.

Contamination by $\mathrm{CP}$ has been detected in work environments at hospitals e.g. in pharmacies and in hospital departments handling antineoplastic drugs. Wipe sampling is a common way to monitor surface contamination. Several wipe sampling methods have been used in earlier studies and CP was detected as a surface contaminant in many of the workplaces that were investigated. ${ }^{10-15}$ However, validation of these methods has been scarce. Larson et al. evaluated different types of tissues but only two types of wipe tissues were tested. ${ }^{16}$ Furthermore, among the previous studies only Schmaus et al. used an internal standard which is not present in the studied work environments. ${ }^{15}$ Most of the methods used either no internal standard or ifosfamide, another widely used antineoplastic drug, as internal standard. In the study by Schmaus et al. the stability of wipe samples containing $\mathrm{CP}$ was investigated but only over four days. ${ }^{15}$ In addition, the sensitivities of the previous methods have not been high enough to detect and evaluate trace contamination with $\mathrm{CP}$.

For measurements of particulate matter of $\mathrm{CP}$ in air, stationary and personal methods have previously been developed. ${ }^{10,11,13,17-19}$ These methods have been used to study air concentrations of $\mathrm{CP}$ at different workplaces. In previous studies different types of filters have been used to collect particles of CP. However, it may not be sufficient to measure particles in the air. The vapour pressure of $\mathrm{CP}$ has been determined by Opiolka et al. and was found to be $3.3 \mathrm{mPa}$ at $20{ }^{\circ} \mathrm{C}^{20}$ The vapour pressure is low but not negligible. Thus, gaseous CP may also be present in the work environments where $\mathrm{CP}$ is handled. In one recent study a stationary method based on a filter connected to a cryogenic-trap was developed to determine both particulate and gaseous CP in air. ${ }^{21}$ Measurements with the developed method were carried out in two hospital pharmacies. In some samples concentrations of gas up to $13 \mu \mathrm{g} \mathrm{m}^{-3}$ were detected. However, it is important that the sampling method is portable and easy to use. A method for air sampling of gaseous $\mathrm{CP}$ based on solid sorbent media was developed by Larson et al. ${ }^{22}$ The method for air monitoring was accurate for measurements of $\mathrm{CP}$ concentrations from less than $1.0 \mu \mathrm{g} \mathrm{ml}^{-1}$ to $>1.0 \mathrm{mg} \mathrm{ml}^{-1}$, but a more sensitive method is needed to detect trace amounts of $\mathrm{CP}$ in the air. Several air methods used either no internal standard or ifosfamide as internal standard. 
The aim of this current investigation has been to develop and validate a sensitive method to determine trace contamination with $\mathrm{CP}$ at surfaces. In addition, a method for personal sampling of CP in air, both as particles and gas, has also been developed and validated. The developed methods have been used in an application to measure contamination of $\mathrm{CP}$ in a hospital pharmacy.

\section{Experimental}

\section{Chemicals}

Cyclophosphamide monohydrate (purity 99.5\%) was purchased from Sigma-Aldrich Chemie (Schnelldorf, Germany). ${ }^{2} \mathrm{H}_{6}$-labelled cyclophosphamide (CP-D6; purity $97 \%$ ) was from Phychem (Bergisch Gladbach, Germany) and ifosfamide (Holoxan; purity $>98 \%$ ) was obtained from ASTA Medica (Frankfurt am Main, Germany). Ethyl acetate (HPLC 99.8\%) and methanol (HPLC) were from Lab-Scan (Dublin, Ireland). Acetic acid glacial (p.a. $>99.8 \%$ ), sodium chloride (p.a. $>99.5 \%$ ) and sodium hydroxide (p.a. $>99.0 \%$ ) were all from Merck (Darmstadt, Germany). Water was purified in a Milli-RQ Water Purifier (Millipore, Billerica, MA, USA).

\section{Wipe tissues and filters}

Wipe tissues used to collect wipe samples were Care Facial tissue, $20.1 \times 21.1 \mathrm{~cm}$ (Katrin, Metsä Tissue, Mariestad, Sweden), Easi-Tex Master Plus, $31 \times 41 \mathrm{~cm}$ (Gunnar Engstrand, Stockholm, Sweden), nonwoven swab, $5 \times 5 \mathrm{~cm}$ (Hartmann-ScandiCare, Anderstorp, Sweden), sterile compress, $10 \times 7.5 \mathrm{~cm}$ (AKLA, Danderyd, Sweden), Kimcare medical wipe, $10.6 \times 20.5 \mathrm{~cm}$ (Kimberly-Clark $\AA$, KimberlyClark, Irving, TX, USA) and Swedish filter paper, $9 \mathrm{~cm}$ diameters (Munktell 50, Munktell Filter, Grycksbo, Sweden). Filters were Fluoropore membrane filter (polytetrafluoroethylene (PTFE, Teflon)), Durapore membrane filter with pore size $0.45 \mu \mathrm{m}$ and $0.65 \mu \mathrm{m}$ (Millipore, Billerica, MA, USA), glass fiber filter type AE (SKC, Eighty Four, PA, USA) and polycarbonate filter $0.1 \mu \mathrm{m}$ (Nuclepore, Pleasanton, CA, USA). All filters had a diameter of $13 \mathrm{~mm}$.

\section{Preparation of standards}

Two stock solutions of $\mathrm{CP}$ were prepared by dissolving weighed amounts of $\mathrm{CP}$ in water. Several working solutions were made from these stock solutions. A stock solution of $\mathrm{CP}$ D6 was prepared by dissolving weighed amounts in water, which was further diluted in water. In the initial experiments ifosfamide was used as internal standard.

\section{Determination of CP on surfaces}

Sampling procedure. Nonwoven swabs were chosen for the collection of wipe samples. A wipe sample was collected within a defined surface area. Plastic frames with internal size of either $10 \times 10 \mathrm{~cm}\left(100 \mathrm{~cm}^{2}\right)$ or $20 \times 20 \mathrm{~cm}\left(400 \mathrm{~cm}^{2}\right)$ were used to define the surface area to be sampled. Each wipe tissue was moistening with $1 \mathrm{ml}$ volume of $0.03 \mathrm{M}$ sodium hydroxide solution. All wipe samples were collected with a uniform sampling procedure by careful wiping in two different directions (up and down, right and left) inside the plastic frame. Two wipe tissues were used in the sampling procedure, one in each direction. After sampling the wipe tissues were placed in wide mouth polyethylene bottles $(50 \mathrm{ml}$; Kautex Textron, Bonn, Germany) and stored at $-20{ }^{\circ} \mathrm{C}$ until the work-up procedure.

Work-up procedure. Aliquots of $20 \mathrm{ml}$ ethyl acetate and

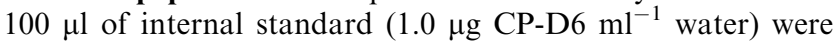
added to each bottle containing two wipe tissues. The bottles were shaken upright for $30 \mathrm{~min}$ with a shake apparatus 4010 Multi-Tube Vortexer (Corning, Medfield, MA, USA). Aliquots of $10 \mathrm{ml}$ of the extracts were transferred into glass test tubes. The samples were then evaporated to dryness under a stream of nitrogen gas at room temperature. Next, $0.15 \mathrm{ml}$ $0.5 \%$ acetic acid was added to each sample, which were then sonicated for $5 \mathrm{~min}$ and transferred into microvials. The samples were stored at $5{ }^{\circ} \mathrm{C}$ until analysis. Standards were prepared by adding $100 \mu \mathrm{l}$ aliquots of the working solution to $1 \mathrm{ml} 0.03 \mathrm{M}$ sodium hydroxide solution.

\section{Determination of $\mathrm{CP}$ in air}

Sampling procedure of solid sorbent samples. Solid sorbent tubes containing a styrene divinyl benzene phase, Bond Elut LMS with a mass of $50 \mathrm{mg}$ and volume of $1 \mathrm{ml}$ (Varian, Harbor City, CA, USA), were used to collect gaseous CP. A flow rate of $140 \mathrm{ml} \mathrm{min}{ }^{-1}$ was applied. The solid sorbent samples were sealed with Parafilm on both sides after sampling.

Work-up procedure of solid sorbent samples. The Bond Elut columns were connected to a vacuum system VacMaster 20 (Sorbent, Västra Frölunda, Sweden) and eluted with $1.5 \mathrm{ml}$ ethyl acetate into test tubes, to which $100 \mu \mathrm{l}$ internal standard were then added. The samples were evaporated to dryness under a stream of nitrogen gas at room temperature. Next, the samples were dissolved in $0.15 \mathrm{ml}$ of $0.5 \%$ acetic acid, sonicated for $5 \mathrm{~min}$ and finally transferred into microvials. The samples were stored at $5{ }^{\circ} \mathrm{C}$ until analysis. Standards of CP were prepared from the working solutions by adding $100 \mu \mathrm{l}$ to $1.5 \mathrm{ml}$ ethyl acetate.

Controlled air system. Air with a defined controlled airflow and relative humidity was obtained by using equipment developed at the National Institute for Working Life in Umeå, Sweden. ${ }^{23,24}$ This was used for the evaluation of the collection of $\mathrm{CP}$ on the solid sorbent tubes. The air producing system consisted of three different glass bubblers containing water, which were coupled in series. The system was driven by compressed air cleaned by a particle filter $(0.01 \mu \mathrm{m})$ and with charcoal. The humidified air stream was branched into seven outlets from which sampling experiments could be performed. The airflow was measured with a rotameter (Rota, Wehr, Germany) and the relative humidity was measured by a hygrometer (HUMICAP 14, Vaisala, Helsinki, Finland).

Sampling procedure for filter samples. The filter used for particle sampling was Durapore membrane filter made of polyvinylidene fluoride (PVDF) and with a pore size of $0.65 \mu \mathrm{m}$ (Millipore, Billerica, MA, USA). The filters had a diameter of

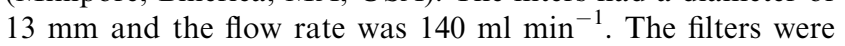
transferred to plastic test tubes after sampling.

Work-up procedure for filter samples. $1 \mathrm{ml}$ ethyl acetate and $100 \mu 1$ internal standard were added to the test tubes containing the filters which were then shaken upright for 30 min with an IKA-VIBRA-VXR (IKA Labortechnik, Staufen, Germany). The extracted liquid was then transferred to glass test tubes. The samples were evaporated to dryness under a stream of nitrogen gas at room temperature. The samples were dissolved in $150 \mu \mathrm{l} 0.5 \%$ acetic acid, sonicated for $5 \mathrm{~min}$ and then transferred into microvials. The samples were stored at $5{ }^{\circ} \mathrm{C}$ until analysis. Standards were prepared by adding aliquots of $100 \mu 1$ working solutions to $1.0 \mathrm{ml}$ ethyl acetate.

\section{Analytical procedure}

Analysis was performed using a Perkin-Elmer Series 200 liquid chromatography system with a Series 200 autosampler 
(Applied Biosystems, Norfolk, CT, USA). The column was a Genesis $\mathrm{C}_{18}(50 \times 2.1 \mathrm{~mm})$ with a particle size of $4 \mu \mathrm{m}$ (Jones Chromatography, Lakewood, CO, USA). The column outlet was coupled to an API 3000 triple quadrupole mass spectrometer (Applied Biosystems/MDS-SCIEX, Toronto, Canada) equipped with an electrospray ionisation (ESI) source. In the beginning of the method development samples were analysed on an API 2000 triple quadrupole mass spectrometer (PE Biosystem, Foster City, CA, USA) instead of the API 3000. The analytical instruments have been validated against each other and found to give similar results.

Gradient elution was carried out with water (solvent A) and methanol (solvent B), both containing $0.5 \%$ acetic acid. A gradient profile including column regeneration with the following proportions $(\mathrm{v} / \mathrm{v})$ of solvent $\mathrm{B}$ was applied $(t(\mathrm{~min}), \% \mathrm{~B})$ : $(0,40),(6,40),(8,100),(8.1,40),(11,40)$. The flow rate of the mobile phase was $0.2 \mathrm{ml} \mathrm{min}^{-1}$ and the injection volume was $20 \mu 1$. The analyses were performed by ESI with ion spray voltage at $3000 \mathrm{~V}$ and temperature at $400{ }^{\circ} \mathrm{C}$. The instrument operated in a positive ion mode using multiple reaction monitoring (MRM) at $m / z$ 263.1/142.1 (analyte fragment) and $\mathrm{m} / \mathrm{z}$ 261.0/140.3 (control fragment) for CP and $m / z 267.1 / 140.3$ for CP-D6. Declustering potential for CP analyte fragment, control fragment and CP-D6 was 40, 42 and $44 \mathrm{~V}$, respectively. Collision energy was $31 \mathrm{~V}$ for CP and $34 \mathrm{~V}$ for CP-D6, respectively. Peak-area ratios between $\mathrm{CP}$ and internal standard were used for quantification. The ratio between the analyte and control fragment of the samples was compared with the ratio between the analyte and control fragment of the standard samples and was not allowed to exceed $20 \%$.

\section{Application of the developed methods}

To test the developed methods in an authentic work environment, a hospital pharmacy in Sweden was contacted. The hospital pharmacy is located at a university hospital and prepares antineoplastic drugs for many different departments at the hospital. The pharmacy prepares all antineoplastic drugs inside microbiological safety cabinets (BSC), class II with a vertical laminar air flow (danLAFß)-o-matic VFRS $1206 \mathrm{E}$, Claus Damm, Humlebæk, Denmark). The pharmacy handles drugs according to the ordinance from the Swedish Work Environment Authority. ${ }^{25}$ Personal protective equipment such as specially adapted protective clothing and double protective gloves of two different materials are used. The pharmacy also used CODAN Spike (CODAN Medizinische Geräte, Lensahn, Germany) to prevent the formation of particles in the BSC during drug preparation.

The sampling device consisted of a filter in a filter cassette connected to a solid sorbent. Low flow pumps of model 222 from SKC (Eighty Four, PA, USA) were used in air sampling. Stationary air samples were collected at four different spots in the pharmacy unit. Air was sampled in the BSC, outside the BSC but near the person working in the BSC (about $50 \mathrm{~cm}$ from the breathing zone), above the waste bin and above a shaker used to prepare stock solutions of CP. Eight-hour sampling was performed. In addition, two wipe samples were collected in the BSC after preparation of an infusion mixture containing $1000 \mathrm{mg} \mathrm{CP}$. Two spots of $400 \mathrm{~cm}^{2}$ on the working area were wiped. The samples were worked-up according to the procedures described above.

\section{Results and discussion}

\section{Wipe samples}

There are a large number of wipe tissues available on the market manufactured in different types of materials and sizes. In previous studies where $\mathrm{CP}$ contamination on surfaces has been examined, different types of wipe tissues, solutions and volumes to moisten wipe tissues with have been used. Also, different surface areas have been sampled and different workup procedures and analytical methods have been applied. So far a standardised sampling procedure for collection of wipe samples on contaminated surfaces has not been developed.

In this study six different types of wipe tissues; Easi-Tex Master Plus, Care Facial tissues, nonwoven swabs, sterile compresses, Kimcare medical wipes and Swedish filter papers were evaluated. Two wipe tissues of each type were spiked with 5,10 and $50 \mathrm{ng}$ of $\mathrm{CP}$ and treated according to the work-up procedure. The mean recoveries for these six wipe tissues ranged between $88-112 \%$. From the result it was possible to exclude three types of tissues. Sterile compresses and filter paper were excluded due to low mean recoveries (88-93\%) and Easi-Tex Master Plus was excluded due to its large size. The three remaining wipe tissues had sufficient desorption capacities. The mean recoveries were between $94-102 \%$ for Care Facial tissues, between $96-106 \%$ for Kimcare medical wipes and between $97-102 \%$ for nonwoven swabs.

The three remaining types of wipe tissues were evaluated to test whether the wipe tissues had to be extracted once or twice. Two wipe tissues of each type were spiked with either 25 or $100 \mathrm{ng}$ of CP and extracted once with $20 \mathrm{ml}$ or twice with $10 \mathrm{ml}$ organic solvent. The recoveries were equal and thus the wipe samples were only extracted once with $20 \mathrm{ml}$ ethyl acetate.

In work environments, e.g. hospital pharmacies and departments, surfaces are generally made of laminate, stainless steel or plastic. Working areas in BSC are frequently made of stainless steel and working areas outside BSC are often made of stainless steel or laminate. The floors are mostly made of some type of plastic material. The absorption capacity of the wipe tissues Care Facial, Kimcare medical wipes and nonwoven swabs were investigated by wiping surfaces made of different materials. CP was dissolved in either water or methanol and $100 \mu \mathrm{l} \mathrm{CP}$ solutions containing either 5 or $100 \mathrm{ng}$ of CP were added to the surfaces. The solution was spread out within an area of $100 \mathrm{~cm}^{2}$ limited by a plastic frame and wipe sampling were performed on both liquid and evaporated spillage of CP. Liquid spillage consisted of CP dissolved in water. Evaporated spillage consisted of CP dissolved in methanol. The methanol was allowed to evaporate before the surface was wipe sampled. The results of the investigation are presented in Table 1. Nonwoven swabs had the highest recoveries, between $87-102 \%$, and the coefficient of variation $(\mathrm{CV})$ ranged between $1-7 \%$, for liquid spillage. For evaporated spillage the recoveries were between $78-106 \%$ and the $\mathrm{CV}$ ranged between $3-10 \%$. Wipe sampling on plastic surface material resulted in lower recoveries than the other surface materials due to the rough and uneven surface. Nonwoven swab had the best and the highest absorption capacity of CP from these different surface materials. This wipe tissue was also most practically applicable. Thus, nonwoven swab was chosen and was used throughout in the rest of this investigation.

The size of the sampling area was also evaluated. To study if the mean recovery of $\mathrm{CP}$ differs between different sampling areas, $5 \mathrm{ng} \mathrm{CP}$ were dissolved in $100 \mu \mathrm{l}$ methanol and spiked to surfaces areas of either 100 or $400 \mathrm{~cm}^{2}$, both limited by plastic frames. Wipe sampling of evaporated spillage was performed on surfaces made of laminate, stainless steel and plastic flooring material. Wipe sampling of surfaces within an area of $100 \mathrm{~cm}^{2}$ resulted in mean recoveries between $78-95 \%$. Wipe sampling of surfaces within an area of $400 \mathrm{~cm}^{2}$ resulted in mean recoveries between $84-92 \%$. Slightly higher recoveries were obtained for the smaller area for sampling on surface materials made of laminate and stainless steel. The recovery was higher for the larger sampling area made of plastic flooring material than for the smaller area. If possible it is preferable to sample a larger area compared to a smaller one. The likelihood of detecting spillage of CP increases with increasing sampling area but it is unpractical to sample too large a surface area. 
Table 1 Summary of wipe sampling on surfaces made of different materials with (a) liquid and (b) evaporated spillage of $\mathrm{CP}$

\begin{tabular}{lllll} 
& & & Mean \\
& Surface & Spike & recovery & \\
& CV \\
Tissue & material & amount $/$ ng & $(\%)$ & $(\%)$ \\
\hline
\end{tabular}

(a)

Kimcare medical wipes Laminate

Kimcare medical wipes Plastic flooring 5

Kimcare medical wipes Stainless steel 5

Kimcare medical wipes Laminate $\quad 100$

Kimcare medical wipes Plastic flooring 100

Kimcare medical wipes Stainless steel 100

Nonwoven swabs Laminate 5

Nonwoven swabs Plastic flooring 5

Nonwoven swabs Stainless steel 5

Nonwoven swabs Laminate 100

Nonwoven swabs Plastic flooring 100

Nonwoven swabs Stainless steel 100

Care Facial

Care Facial

Care Facial

Care Facial

Care Facial

Care Facial

Laminate 5

Plastic flooring 5

Stainless steel 5

Laminate $\quad 100$

Plastic flooring 100

Stainless steel 100

(b)

$\begin{array}{lll}\text { Kimcare medical wipes } & \text { Laminate } & 5 \\ \text { Kimcare medical wipes } & \text { Plastic flooring } & 5\end{array}$

Kimcare medical wipes Stainless steel 5

Kimcare medical wipes Laminate 100

Kimcare medical wipes Plastic flooring 100

Kimcare medical wipes Stainless steel 100

Nonwoven swabs Laminate 5

Nonwoven swabs Plastic flooring 5

Nonwoven swabs Stainless steel 5

Nonwoven swabs Laminate 100

Nonwoven swabs Plastic flooring 100

Nonwoven swabs Stainless steel 100

Care Facial

Care Facial

Care Facial

Care Facial

Care Facial

Laminate 5

Plastic flooring 5

Stainless steel 5

Laminate $\quad 100$

Plastic flooring 100

Care Facial

Stainless steel 100

${ }^{a}$ Mean of 10 samples.

When wipe sampling different types of surfaces it is important to use a solution that has the capacity to effectively clean the surfaces. In many other studies and publications a weak sodium hydroxide solution has been used in wipe sampling. ${ }^{10,12,14}$ Thus, we chose to moisten the wipe tissues with a $0.03 \mathrm{M}$ sodium hydroxide solution. The recoveries have been high for all three surface materials. Therefore sodium hydroxide seems to be a suitable solution for wipe sampling.

\section{Air samples}

Work-up procedure of solid sorbent tubes. Initial results indicated that CP binds irreversibly to glass surfaces and thus sorbent tubes without glass were chosen. Two types of plastic tubes with different polymeric sorbent phases, Bond Elut LMS and Abselut NEXUS with a mass of $30 \mathrm{mg}$ and volume of $1 \mathrm{ml}$ (Varian, Harbor City, CA, USA), were chosen and evaluated. To test the adsorption and desorption capacity of these tubes, $10 \mu \mathrm{l}$ methanol containing $200 \mathrm{ng} \mathrm{CP}$ were injected into two sorbent tubes of each type. The tubes were kept at room temperature for a couple of minutes until the methanol had evaporated. The samples were then eluted according to the
Table 2 Amounts of CP quantified in sorbent tubes spiked with either 5 or $200 \mathrm{ng}$ of CP. Air with a flow of $200 \mathrm{ml} \mathrm{min}^{-1}$ and a relative humidity of either 5 or $60 \%$ was passed through the sorbent tubes for $8 \mathrm{~h}$

\begin{tabular}{lccll}
\hline $\begin{array}{l}\text { Solid sorbent } \\
\text { tube }\end{array}$ & $\begin{array}{l}\text { Spike } \\
\text { amount/ng }\end{array}$ & $\begin{array}{l}\text { Relative } \\
\text { humidity }(\%)\end{array}$ & $\begin{array}{l}\text { Mean recovery } \\
\text { of } \mathrm{CP}^{a} / \mathrm{ng}\end{array}$ & $\begin{array}{l}\mathrm{CV}^{a} \\
(\%)\end{array}$ \\
\hline Bond Elut & 5 & 5 & 86 & 7 \\
Bond Elut & 5 & 60 & 87 & 5 \\
Bond Elut & 200 & 5 & 98 & 3 \\
Bond Elut & 200 & 60 & 99 & 2 \\
${ }^{a}$ Mean of 6 samples. & & & \\
\hline
\end{tabular}

work-up procedure. The mean extraction recoveries of Bond Elut and Abselut were 97 and 89\%, respectively. Thus, Bond Elut was chosen and used further on in this investigation.

Sampling procedure of sorbent tubes. Different parameters such as relative humidity (5 and 60\%) and spike amount of CP ( 5 and $200 \mathrm{ng}$ ) were evaluated using the controlled air system. Air with a constant flow of $200 \mathrm{ml} \mathrm{min}{ }^{-1}$ was passed through the sorbent tubes for $8 \mathrm{~h}$. Sampling was performed at a temperature of $20{ }^{\circ} \mathrm{C}$. After sampling each sorbent tube was worked-up according to the described procedure. The results are shown in Table 2. Mean recoveries ranged between 86-99\%. Tubes spiked with $5 \mathrm{ng}$ of CP provided lower mean recovery and higher $\mathrm{CV}$ than tubes spiked with $200 \mathrm{ng}$ of $\mathrm{CP}$. The relative humidity did not appear to have an effect upon the recovery of $\mathrm{CP}$.

To study how the sampling time affects the recovery, four sorbent tubes were spiked with $200 \mathrm{ng}$ of $\mathrm{CP}$ and connected to the outlets of the controlled air system. Air with a relative humidity of $20 \%$ was passed through the tubes. Two tubes were sampled for $1 \mathrm{~h}$ and two tubes were sampled for $8 \mathrm{~h}$. The mean recovery was $99 \%$ and $97 \%$ for the tubes sampled for $1 \mathrm{~h}$ and $8 \mathrm{~h}$, respectively. This indicates that it is possible to sample $\mathrm{CP}$ for up to $8 \mathrm{~h}$.

To study how temperature affected the evaporation of $\mathrm{CP}$, solid sorbent tubes were connected to Teflon tubes with a length of $5 \mathrm{~cm}$. These tubes were connected to each outlet of the controlled air system. A wad made of Teflon wool was placed into each tube. Aliquots of $10 \mu \mathrm{l}$ methanol containing $200 \mathrm{ng}$ CP were injected into the wads. Two Teflon tubes were at room temperature and two tubes were placed in a heater at $140{ }^{\circ} \mathrm{C}$. An air stream with a relative humidity of $20 \%$ and a flow of $200 \mathrm{ml} \mathrm{min}{ }^{-1}$ passed through the Teflon tubes and into the solid sorbent tubes for $1 \mathrm{~h}$. The mean extraction recoveries from the solid sorbent tubes are presented in Table 3. The tubes at room temperature had a very low mean recovery as only $11 \%$ of the CP was converted into gaseous form and transferred with the air stream into the solid sorbent tubes. At the higher temperature a higher recovery was received as $66 \%$ was found in the solid sorbent tubes. This shows that CP may be present in air as a vapour at room temperature.

\section{Filter samples}

The usual way to sample particles in air is to use a filter placed in a filter cassette, which is connected to an air-sucking pump.

Table 3 Recovery of CP quantified in sorbent tubes after $1 \mathrm{~h}$ sampling

\begin{tabular}{lll}
\hline Temperature $/{ }^{\circ} \mathrm{C}$ & Mean recovery ${ }^{a}(\%)$ & $\mathrm{CV}^{a}(\%)$ \\
\hline 20 & 11 & 24 \\
140 & 66 & 11 \\
${ }^{a}$ Mean of 2 samples. & & \\
\hline
\end{tabular}


Table 4 Recovery of filters spiked with $10 \mathrm{ng}$ of CP

\begin{tabular}{lcc}
\hline Filter type & Mean recovery $^{a}(\%)$ & $\mathrm{CV}^{a}(\%)$ \\
\hline PTFE & 97 & 7 \\
PVDF $(0.65 \mu \mathrm{m})$ & 101 & 6 \\
PVDF $(0.45 \mu \mathrm{m})$ & 102 & 4 \\
Polycarbonate & 84 & 19 \\
Glass fiber & 105 & 7 \\
${ }^{a}$ Mean of 10 samples. & & \\
\end{tabular}

There are many different types of filters commercially available and in previous studies different types of filter have been used to sample particles of $\mathrm{CP}$. In this investigation filters made of four different types of materials, PTFE, PVDF, polycarbonate and glass fiber, were evaluated.

The filters were evaluated by spiking ten filters of each type with $10 \mathrm{ng}$ of CP. CP was dissolved in methanol and added in $10 \mu \mathrm{l}$ aliquots to the filters. After a few minutes when the methanol had evaporated the filter was placed in a plastic test tube and stored at $-20{ }^{\circ} \mathrm{C}$ until analysis. The mean extraction recoveries of the filters ranged between $84-105 \%$ (Table 4). Filters made of polycarbonate had the lowest mean recovery, $84 \%$ and the highest CV, 19\%. Filters made of glass fiber were not suitable for use because of break down of the filters during the work-up procedure. The remaining filters, one filter made of PTFE and two filters made of PVDF, showed a mean recovery between $97-102 \%$ and a CV between $4-7 \%$. These filters therefore seemed to be equally applicable. The PVDF Durapore filter, however, was much cheaper, and, due to that, the Durapore filter with a pore size of $0.65 \mu \mathrm{m}$ was chosen.

\section{Quantitative analysis}

Standard curve. Standards were prepared by adding different amounts of CP to the same matrix as the sample, and the workup procedure was then performed. To make standard curves, weighted $(1 / x)$ linear regression was used. Linear standard curves with $r>0.99$ were always obtained.

Limit of detection. The limit of detection was defined and calculated as the analyte concentration giving a peak-area ratio equal to the mean of the blank peak-area ratio plus three times the standard deviation in the blanks. ${ }^{26}$ Ten blanks of wipe samples, solid sorbent samples and filter samples were analysed for the determination of the mean and the standard deviation of the blank peak-area ratio. The limit of detection was determined to be $0.02 \mathrm{ng}$ CP per wipe sample $\left(0.05 \mathrm{pg} \mathrm{cm}^{-2}\right.$ for $400 \mathrm{~cm}^{2}$ area), $0.02 \mathrm{ng} \mathrm{CP}$ per sample $\left(0.02 \mathrm{ng} \mathrm{ml}^{-1}\right)$ for the filter methods and $0.03 \mathrm{ng}$ CP per sample $\left(0.02 \mathrm{ng} \mathrm{ml}^{-1}\right)$ for the solid sorbent method. Limits of detection of the developed methods in this study were much lower compared with earlier studies for wipe and air methods. ${ }^{10-19}$

Precision. The within-day precision of the methods was evaluated by analysing six wipe, solid sorbent and filter samples containing $5 \mathrm{ng} \mathrm{CP}$. The $\mathrm{CV}$ was $2 \%$ for the wipe samples, $5 \%$ for the solid sorbent samples and $4 \%$ for the filter samples. Analysing duplicates of samples containing 1,2, 3, 4, 5 and $20 \mathrm{ng}$ CP evaluated the between-day precision of the methods. The duplicates were analysed on 5 different days within a period of four weeks. The CV was between $2-5 \%$ for the wipe samples, between $4-6 \%$ for the sorbent samples and between $3-8 \%$ for the filter samples.

\section{Stability of wipe samples and air samples}

Storage of wipe and air samples containing CP under different conditions was performed to test the stability of $\mathrm{CP}$. Storage
Table 5 Mean recovery and standard deviation of six spiked (a) wipe, (b) sorbent tubes and (c) filter samples stored at different temperatures and time

\begin{tabular}{|c|c|c|c|}
\hline \multirow[b]{2}{*}{ Storage time/days } & \multicolumn{3}{|c|}{ Storage temperature $/{ }^{\circ} \mathrm{C}$} \\
\hline & 20 & 5 & -20 \\
\hline \multicolumn{4}{|l|}{ (a) } \\
\hline 0 & $98 \pm 2$ & $98 \pm 2$ & $98 \pm 2$ \\
\hline 1 & $96 \pm 2$ & $97 \pm 2$ & $97 \pm 1$ \\
\hline 2 & $94 \pm 4$ & $96 \pm 3$ & $96 \pm 2$ \\
\hline 7 & $89 \pm 4$ & $99 \pm 2$ & $99 \pm 2$ \\
\hline 14 & $83 \pm 5$ & $101 \pm 3$ & $100 \pm 4$ \\
\hline 21 & $75 \pm 5$ & $95 \pm 3$ & $100 \pm 3$ \\
\hline 28 & $66 \pm 3$ & $100 \pm 3$ & $104 \pm 2$ \\
\hline 56 & $52 \pm 15$ & $108 \pm 13$ & $107 \pm 5$ \\
\hline \multicolumn{4}{|l|}{ (b) } \\
\hline 0 & $106 \pm 3$ & $106 \pm 3$ & $106 \pm 3$ \\
\hline 1 & $99 \pm 2$ & $106 \pm 4$ & $104 \pm 6$ \\
\hline 2 & $90 \pm 6$ & $98 \pm 5$ & $97 \pm 5$ \\
\hline 7 & $94 \pm 4$ & $101 \pm 10$ & $104 \pm 3$ \\
\hline 14 & $88 \pm 3$ & $92 \pm 3$ & $93 \pm 3$ \\
\hline 21 & $88 \pm 2$ & $86 \pm 10$ & $93 \pm 5$ \\
\hline 28 & $77 \pm 4$ & $90 \pm 11$ & $90 \pm 4$ \\
\hline 56 & $93 \pm 4$ & $101 \pm 3$ & $106 \pm 3$ \\
\hline \multicolumn{4}{|l|}{ (c) } \\
\hline 0 & $102 \pm 4$ & $102 \pm 4$ & $102 \pm 4$ \\
\hline 1 & $96 \pm 10$ & $105 \pm 3$ & $101 \pm 1$ \\
\hline 2 & $101 \pm 3$ & $101 \pm 2$ & $93 \pm 4$ \\
\hline 7 & $94 \pm 1$ & $100 \pm 7$ & $92 \pm 2$ \\
\hline 14 & $95 \pm 2$ & $95 \pm 5$ & $92 \pm 5$ \\
\hline 21 & $86 \pm 6$ & $88 \pm 4$ & $88 \pm 3$ \\
\hline 28 & $87 \pm 1$ & $90 \pm 3$ & $89 \pm 3$ \\
\hline 56 & $99 \pm 3$ & $107 \pm 3$ & $106 \pm 5$ \\
\hline
\end{tabular}

time was up to 2 months. Preparation of wipe samples was performed by moistening two absorbent tissues with $1 \mathrm{ml}$ sodium hydroxide $(0.03 \mathrm{M})$ each. The tissues were placed in bottles and $5 \mathrm{ng} \mathrm{CP}$ dissolved in $100 \mu \mathrm{l}$ water was added to the tissues. The plastic bottle was then capped. The stability of the air samples was tested by adding $5 \mathrm{ng} \mathrm{CP}$ dissolved in $10 \mu \mathrm{l}$ methanol to the solid sorbent tubes and to the filters. The methanol evaporated before the solid sorbent tubes were sealed with Parafilm and the filters were placed in plastic sample tubes with screw caps. Wipe samples and air samples were stored at approximately $20{ }^{\circ} \mathrm{C}, 5{ }^{\circ} \mathrm{C}$ and $-20{ }^{\circ} \mathrm{C}$ for $0,1,2,7,14,21,28$ and $56 \mathrm{~d}$. On each occasion six wipe and air samples from each storing condition were analysed. The samples stored for $0 \mathrm{~d}$ were prepared and analysed after sample preparation. The results of the wipe samples showed that $\mathrm{CP}$ is a quite stable compound (Table 5a). Wipe samples can be stored at temperatures of $5{ }^{\circ} \mathrm{C}$ or $-20{ }^{\circ} \mathrm{C}$ for at least 2 months. No loss of $\mathrm{CP}$ was observed in wipe samples stored at room temperature for $2 \mathrm{~d}$. The results from the storage of sorbent tube and filter samples are shown in Table 5b-c. Sorbent and filter samples can be stored for at least 2 months without any loss of CP. After a week at room temperature $90 \%$ of the added CP was still present. The results showed that wipe and air samples can be transported for a couple of days at room temperature without significant losses of CP. Schmaus et al. stored wipe samples for one and four days at room temperature and $4{ }^{\circ} \mathrm{C}$ and found that wipe samples were stable for four days at $4{ }^{\circ} \mathrm{C}$ and one day at room temperature. ${ }^{15}$

\section{Application of the developed methods}

During the exposure measurement at the hospital pharmacy 5 infusion mixtures containing $\mathrm{CP}$ were prepared. In this 
procedure a defined volume of $\mathrm{CP}$ from a stock solution was transferred into infusion bags containing e.g. $250 \mathrm{ml}$ sodium chloride solution. A total of $13.8 \mathrm{~g} \mathrm{CP}$ were handled in the $\mathrm{BSC}$ during the measurement.

The stationary air measurements were performed over $8 \mathrm{~h}$. The air sampling device consisted of a filter that was in series with a solid sorbent since it is important to measure both particles and gas of $\mathrm{CP}$ in air. This has previously been demonstrated by Kiffmeyer et al. ${ }^{21}$ A mean air volume of $67 \mathrm{~L}$ (range 64-73 L) was sucked through the air sampling device. No CP above the limit of detection could be found in any of the filter samples nor in any of the sorbent samples. In this study it has previously been demonstrated that only a small fraction of $\mathrm{CP}$ is converted into gaseous form at room temperature. The likelihood of finding $\mathrm{CP}$ in air during the measurements at the hospital pharmacy was assessed to be largest inside the BSC. If any gaseous $\mathrm{CP}$ was present inside the BSC during the air measurement, it may have been ventilated, since the BSC is connected to the exhaust ventilation, or it may have been attached to surfaces inside the BSC since the initial studies showed that vaporized $\mathrm{CP}$ was efficiently attached to surfaces. A reason why no particles of $\mathrm{CP}$ were detected in the air in the BSC may be explained by the use of spikes. The spikes contained a filter with a pore size of $0.2 \mu \mathrm{m}$, which is expected to prevent the particles from entering the air in the BSC in association with drug preparation.

After one preparation of an infusion mixture containing $1000 \mathrm{mg} \mathrm{CP}$, two wipe samples were collected in the BSC. Amounts of 1.3 and $1.4 \mathrm{ng} \mathrm{CP}$ were detected in the two samples and these correspond to 3.3 and $3.5 \mathrm{pg} \mathrm{cm}^{-2}$, respectively. The pharmacy prepared antineoplastic drugs on disposable absorbent sheets, which had a plastic-coated underneath. These sheets almost covered the whole working area in the BSC. The sheet was removed before wipe sampling. This can explain why no high amounts of $\mathrm{CP}$ were found on the working area in the BSC. In this application it was demonstrated that the developed method for wipe sampling could detect trace contamination of $\mathrm{CP}$ in an authentic work environment.

\section{Acknowledgements}

The authors thank Ms AnnSofie Fyhr and Ms Lena Jernström from the Hospital pharmacy, Lund University Hospital, for their help and Ms Gertrud Wohlfart for her technical assistance. This work was supported by the Swedish Council for Work Life Research, the Swedish Research Council and the Medical Faculty at Lund University in Lund, Sweden.

\section{References}

1 P. J. Sessink, N. S. Friemel, R. B. Anzion and R. P. Bos, Int. Arch. Occup. Environ. Health, 1994, 65, 401.

2 A. S. Ensslin, A. Pethran, R. Schierl and G. Fruhmann, Int. Arch. Occup. Environ. Health, 1994, 65, 339.

3 A. S. Ensslin, Y. Stoll, A. Pethran, A. Pfaller, H. Rommelt and G. Fruhmann, Occup. Environ. Med., 1994, 51, 229.

4 P. J. Sessink, J. L. Timmersmans, R. B. Anzion and R. P. Bos, J. Occup. Med., 1994, 36, 79.

5 A. Pethran, R. Schierl, K. Hauff, C. H. Grimm, K. S. Boos and D. Nowak, Int. Arch. Occup. Environ. Health, 2003, 76, 5.

6 O. Nygren and C. Lundgren, Int. Arch. Occup. Environ. Health, 1997, 70, 209.

7 N. Brock, Cancer Res., 1989, 49, 1.

8 International Agency for Research on Cancer, IARC monographs on the evaluation of the carcinogenic risk to humans. Vol 26. Some antineoplastic and immunosuppressive agents, Lyon, France, 1981.

9 International Agency for Research on Cancer, IARC monographs on the evaluation of the carcinogenic risk to humans. Suppl. 7. Overall evaluation of carcinogenicity: An updating of IARC monographs volumes 1-42, Lyon, France, 1987.

10 P. J. Sessink, R. B. Anzion, P. H. Van den Broek and R. P. Bos, Pharm. Weekbl. Sci., 1992, 14, 16.

11 J. J. McDevitt, P. S. Lees and M. A. McDiarmid, J. Occup. Med., $1993,35,57$.

12 T. H. Conner, R. W. Anderson, P. J. Sessink, L. Broadfield and L. A. Power, Am. J. Health Syst. Pharm., 1999, 56, 1427.

13 C. Minoia, R. Turci, C. Sottani, A. Schiavi, L. Perbellini, S. Angeleri, F. Draicchio and P. Apostoli, Rapid Commun. Mass. Spectrom., 1998, 12, 1485.

14 A. Pethran, R. Schierl and G. Schmaus, Krankenhauspharmazie, 2001, 22, 11 .

15 G. Schmaus, R. Schierl and S. Funck, Am. J. Health Syst. Pharm., 2002, 59, 956.

16 R. R. Larson, M. B. Khazaeli and H. K. Dillon, Am. J. Health Syst. Pharm., 2002, 59, 270

17 A. deWerk Neal, R. A. Wadden and W. L. Chiou, Am. J. Hosp. Pharm., 1983, 40, 597.

18 L. Pyy, M. Sorsa and E. Hakala, Am. Ind. Hyg. Assoc. J., 1988, 49, 314 .

19 M. Sorsa, L. Pyy, S. Salomaa, L. Nylund and J. W. Yager, Mutat. Res., 1988, 204, 465.

20 S. Opiolka, W. Mölter, R. Goldschmidt, E. Erich and G. Schöppe, Krankenhaus Technik, 1998, 56.

21 T. K. Kiffmeyer, C. Kube, S. Opiolka, K. G. Schmidt, G. Schöppe and P. J. M. Sessink, Pharm. J., 2002, 268, 331.

22 R. R. Larson, M. B. Khazaeli and H. K. Dillon, Appl. Occup. Environ. Hyg., 2003, 18, 120.

23 K. Andersson, J.-O. Levin, R. Lindahl and C.-A. Nilsson, Chemosphere, 1984, 13, 437.

24 J.-O. Levin, R. Lindahl and K. Andersson, Environ. Sci. Technol., 1986, 20, 1273

25 AFS 1999:11, Cytostatika och andra läkemedel med bestående toxisk effekt [Cytostaticsand other drugs with permanent toxic effects], The Swedish Work Environment Authority, Solna, Sweden, 1999.

26 J. C. Miller and J. N. Miller, Statistics for Analytical Chemistry, 3rd edn., Ellis Horwood, Chichester, UK, p. 115. 